\title{
Renal Clearance for Dose Interval
}

National Cancer Institute

\section{Source}

National Cancer Institute. Renal Clearance for Dose Interval. NCI Thesaurus. Code C122050.

The clearance of a substance from the blood by the kidneys, calculated using the area under the curve over the dosing interval. 